\title{
Chopped basalt fibres: A new perspective in reinforcing poly(lactic acid) to produce injection moulded engineering composites from renewable and natural resources
}

\author{
T. Tábi ${ }^{1,2 *}$, P. Tamás $^{1,2}$, J. G. Kovács ${ }^{2}$ \\ ${ }^{1}$ MTA-BME Research Group for Composite Science and Technology, Müegyetem rkp. 3., H-1111 Budapest, Hungary \\ ${ }^{2}$ Department of Polymer Engineering, Faculty of Mechanical Engineering, Budapest University of Technology and \\ Economics, Muegyetem rkp. 3., H-1111 Budapest, Hungary
}

Received 4 July 2012; accepted in revised form 11 September 2012

\begin{abstract}
This paper focuses on the reinforcing of Poly(lactic acid) with chopped basalt fibres by using silane treated and untreated basalt fibres. Composite materials with 5-10-15-20-30-40 wt \% basalt fibre contents were prepared from silane sized basalt fibres using extrusion, and injection moulding, while composites with $5-10-15 \mathrm{wt} \%$ basalt fibre contents were also prepared by using untreated basalt fibres as control. The properties of the injection moulded composites were extensively examined by using quasi-static (tensile, three-point bending) and dynamic mechanical tests (notched and unnotched Charpy impact tests), dynamic mechanical analysis (DMA), differential scanning calorimetry (DSC), heat deflection temperature (HDT) analysis, dimensional stability test, as well as melt flow index (MFI) analysis and scanning electron microscopic (SEM) observations. It was found that silane treated chopped basalt fibres are much more effective in reinforcing Poly(lactic acid) than natural fibres; although basalt fibres are not biodegradable but they are still considered as natural (can be found in nature in the form of volcanic rocks) and biologically inert. It is demonstrated in this paper that by using basalt fibre reinforcement, a renewable and natural resource based composite can be produced by injection moulding with excellent mechanical properties suitable even for engineering applications. Finally it was shown that by using adequate drying of the materials, composites with higher mechanical properties can be achieved compared to literature data.
\end{abstract}

Keywords: biodegradable polymers, polymer composites, poly(lactic acid), chopped basalt fibres, injection moulding

\section{Introduction}

In the $21^{\text {st }}$ century, due to the increasing environmental consciousness renewable resource based and inherently biodegradable polymers gain more and more role. These materials can be fully synthetized from biomass or previously not utilized agricultural feedstock and during their biodegradation harmless materials like water, carbon-dioxide and humus are produced, where the latter can be used to grow agricultural plants, so thus it can be easily seen that these materials fit into the life cycle of nature and also fit into the train of thoughts of sustainable development [1-3]. It is also believed that in the near future biodegradable polymers will be used for producing plastic products with short term applications, however nowadays in most cases for these applications still unnecessarily durable petrol-based plastics are used, what causes more and more waste management problems due to their not complete recyclability.

One of the most promising renewable resources to produce biopolymers is starch. Starch can be found all over the world in abundant amounts, because starch containing agricultural plants like corn, wheat, potato are grown extensively in a lot of countries. In the last few decades much research has

\footnotetext{
$\overline{{ }^{*} \text { Corresponding author, e-mail: tabi@pt.bme.hu }}$

(c) BME-PT
} 
been made to make starch processable with conventional plastic processing equipment, and as a result thermoplastic starch (TPS) was developed and extensively researched [4-6]. Although TPS is cheap, its numerous drawbacks like low mechanical properties, high shrinkage, and water solubility retarded its widespread usage. Nowadays TPS together with Poly( $\varepsilon$-caprolactone) (PCL) is used as a compound and commercialised under trade name Mater-Bi (Novamont, Italy). Another possible way to utilise starch is its fermentation in the presence of sugar into lactic acid, what can be further polymerised into Poly(lactic acid) (PLA). In the last decade PLA was in the focus of interest, and it became the most promising biopolymers of all due to its excellent mechanical properties, easy processing by conventional equipment, low shrinkage, reasonable price and harmless biodegradation capability [7-9]. Although PLA is already commercialised and more and more PLA products are on the market, these products are still mainly related to packaging industry, even so the high strength and stiffness of PLA suggest it to be used as the matrix of a durable engineering composite material, but its low heat deflection temperature (HDT) and low impact strength still retards its usage as a high performance composite.

Lots of efforts have been made to further reinforce PLA with typically natural plant fibres [10-16] or even with glass fibres [17] to make a biocomposite for applications with higher demand then packaging. In most cases by adding natural plant fibres to PLA higher increase of mechanical properties occurred when solvent casting $[10,11]$, pultrusion [12], extrusion followed by compression [13], filmstacking $[14,15]$, compression followed by injection moulding [16] processes were used compared to the conventional and most productive extrusion followed by injection moulding process [17, 18]. This is probably due to the reduced length of the natural fibres in the latter technology. Furthermore, the increase of HDT due to the incorporation of various fibres is only a few times experienced. Iwatake et al. [10] demonstrated that by using solvent casting method and micro-fibrillated cellulose (MFC) fibres a cellulose fibre network interconnected by hydrogen bonds was developed which resisted the applied stress independently of the softening of PLA during dynamic mechanical analysis (DMA) tests. By using the above mentioned processes to increase HDT and impact strength it is crucial to have strong connection between the fibres and the PLA, and the adequate quantity and quality (according to stiffness and length) of reinforcing fibres is also important, which will prevent the well-known high stiffness loss of amorphous PLA products above glass transition temperature $\left(T_{\mathrm{g}}\right)$. However, by adding natural plant fibres to reinforce PLA, the real breakthrough did not occur because in order to gain significant reinforcing effect especially in the desired impact strength low productivity processes like solvent casting or film stacking method have to be used but to commercialise PLA based composites and make complicated 3D shaped, and accurate parts highly productive production technologies like injection moulding should be applied.

Besides natural fibres, a promising alternative may be the usage of basalt fibres, which is a novel reinforcement for composites. Although basalt fibres are not biodegradable but still considered as natural, because they can be produced by using basalt (volcanic) rocks, which can be found in nature and virtually in every country around the globe. Moreover, basalt is biologically inert, and the weathering of basalt rocks increase the mineral content of soil which further strengthens its natural character. Basalt fibres are typically produced by two different technologies: Junkers method and spinneret technology [19]. The shorter basalt fibres are prepared by the Junkers method and the continuous fibres are prepared by the spinneret technology [20]. Its mechanical properties and chemical composition is similar to the glass fibre, and it can be used between -200 and $600^{\circ} \mathrm{C}$ without the significant loss of mechanical properties [21, 22]. Basalt fibres are biologically inert as well as environmentally friendly and can be used in very aggressive environments too $[23,24]$. The surface of the basalt fibres can be modified easily, thus they can be used as reinforcement fibres for composites [25, 26]. Deák et al. [27] investigated the influence of different coupling agents on the mechanical and thermomechanical properties of basalt fibre reinforced Polyamide 6 (PA6). The tensile, flexural and impact strengths were improved in the highest level by the type of 3-glycidoxypropyltrimethoxysilane sizing. The suitability of that sizing material in a wide temperature range was proven by DMA tests.

Basalt fibres seem to be a good alternative to reinforce PLA, however, the number of papers in basalt 
fibre reinforced PLA is very limited [28-30]. Liu et al. [28] demonstrated that basalt fibres with the adequate sizing can improve tensile, flexural and impact strength of PLA more significant as plant fibres. It was also found that by using $20 \mathrm{wt} \%$ of basalt fibres and $20 \mathrm{wt} \%$ of ethylene-acrylate-glycidyl methacrylate copolymer (EAGMA) the impact strength can be further increased up to $34 \mathrm{~kJ} / \mathrm{m}^{2}$ from the original value of PLA of $19 \mathrm{~kJ} / \mathrm{m}^{2}$ (unnotched Charpy test results). Finally the authors stated that the fibres are strongly bonded to the PLA because no gap was found at the fibre-matrix interface. Kurniawan et al. [29] used atmospheric pressure glow discharge plasma polymerization as surface treatment of basalt fibres and analysed the adhesion between the fibres and PLA in hot pressed composites. It was found that by increasing the plasma polymerisation time the tensile strength of the composites increased compared to PLA when the reaction time was higher than 3 minutes. Although the plasma polymerised fibres seem to be well wetted by the PLA, the tensile strength was lower compared to results from Liu et al. [28]. Finally Chen et al. [30] successfully produced PLA based scaffolds reinforced with basalt fibres. They proved that the basalt fibres retard degradation rate of the scaffold, thus most likely decrease inflammatory responses caused by acidification. Moreover, basalt fibres did not notably affect osteoblast viability and growth which means that basalt fibre reinforced PLA scaffolds can be potentially used in hard tissue repair.

According to these results basalt fibres seem to be a good selection to reinforce PLA, because PLA based composites with higher mechanical properties can be achieved compared to natural plant fibre reinforcement. However, the widespread analysis of the various mechanical, thermal, flow and dimensional stability properties of injection moulded basalt fibre reinforced PLA based composites can be only partly found in the literature. Thus, this paper focuses on the comprehensive usability analysis of chopped basalt fibres with and without silane treatment as potential reinforcing fibre for injection moulded, renewable and natural resource based PLA composites as high performance, durable engineering materials.

\section{Materials, processing and experimental}

Semi-crystalline PLA injection moulding grade resin was used for the measurements (type AI1001 from eSUN, Shenzhen, China, with a D-Lactide content of $4 \%$ ). It was dried at $120^{\circ} \mathrm{C}$ for 6 hours prior to extrusion. A somewhat high drying temperature was chosen, because according to our previous research [31] simply by using adequate drying, significantly higher adhesion could be developed between the phases, because the residual moisture could induce degradation and it could also weaken the adhesion between the fillers or fibres and the matrix material. Chopped basalt fibres produced with Junkers method from Kameny Vek (Dubna, Russia) were obtained with the company's own silane treatment type KV-12 developed especially for strong adhesion with polyesters. The average diameter of the fibres was $13 \mu \mathrm{m}$, while the initial length was $10 \mathrm{~mm}$. The fibres were also dried along with the PLA resin to remove residual moisture. Some of the basalt fibres were heated to $600^{\circ} \mathrm{C}$ to remove silane sizing. The PLA pellets and the treated and untreated (removed silane) basalt fibres were dry blended and extruded by using a LabTech Scientific twin screw extruder (Bangkok, Thailand) (screw diameter $=26 \mathrm{~mm}, L / D=40$ ) equipped with a $2 \mathrm{~mm}$ hole diameter die. A temperature profile of 175-180-185-190 ${ }^{\circ} \mathrm{C}$ (from the hopper to the die) was used with a screw rotational speed of $30 \mathrm{rpm}$. 5-10-15-20-30-40 wt\% basalt fibre composites were prepared with silane treatment (abbreviated as 5BS, 10BS, 15BS, 20BS, 30BS, 40BS) and 5-10$15 \mathrm{wt} \%$ basalt fibre composites with removed treatment for control (abbreviated as 5BN, 10BN, 15BN). The extrudates were pelletized and annealed (crystallised) prior to injection moulding to avoid processing problems (pellet sticking to the screw) caused by cold crystallisation as reported in our previous research [32]. The pellets were injection moulded with an Arburg Allrounder 370S 700-250 injection moulding machine (Lossburg, Germany) equipped with a $30 \mathrm{~mm}$ diameter, $L / D=25$ screw. The applied injection moulding parameters can be seen in Table 1.

ISO standard dumbbell, three-point bending and Charpy specimens with a cross-section of $4 \times 10 \mathrm{~mm}$, and $80 \times 80 \mathrm{~mm}$ area, $2 \mathrm{~mm}$ thick flat specimens were injection moulded for the tests.

Tensile and three-point bending tests were performed by using a Zwick Z020 universal testing machine equipped with Zwick BZ 020/TN2S force measuring cell with a force limit of $4 \mathrm{kN}$ using a cross-head speed of $5 \mathrm{~mm} / \mathrm{min}$. Charpy tests were 
Table 1. Injection moulding parameters

\begin{tabular}{|l|c|}
\hline Injection moulding parameter & \multicolumn{1}{|c|}{ Value } \\
\hline Volume & $\begin{array}{l}50 \mathrm{~cm}^{3} \text { (flat specimen) } \\
44 \mathrm{~cm}^{3} \text { (tensile specimen) } \\
42 \mathrm{~cm}^{3} \text { (bending specimen) }\end{array}$ \\
\hline Injection pressure & $\begin{array}{l}\text { Variable according to basalt } \\
\text { fibre content }\end{array}$ \\
\hline Switch-over point & $12 \mathrm{~cm}^{3}$ \\
\hline Injection rate & $50 \mathrm{~cm}^{3} / \mathrm{s}$ \\
\hline Holding pressure & $20 \mathrm{bar}$ \\
\hline Holding time & $30 \mathrm{~s}$ \\
\hline Residual cooling time & $15 \mathrm{~m} / \mathrm{min}$ \\
\hline Screw rotational speed & $30 \mathrm{bar}$ \\
\hline Backpressure & $5 \mathrm{~cm}$ \\
\hline Decompression volume & $5 \mathrm{~cm} / \mathrm{s}$ \\
\hline Decompression rate & $165^{\circ} \mathrm{C}$ \\
\hline Temperature of the first zone & $175^{\circ} \mathrm{C}$ \\
\hline Temperature of the second zone & $180^{\circ} \mathrm{C}$ \\
\hline Temperature of the third zone & $185^{\circ} \mathrm{C}$ \\
\hline Temperature of the fourth zone & $190^{\circ} \mathrm{C}$ \\
\hline Temperature of the fifth zone & $20^{\circ} \mathrm{C}$ \\
\hline Temperature of the mould & \\
\hline
\end{tabular}

performed with a Ceast Resil Impactor impact testing machine equipped with a $15 \mathrm{~J}$ impact energy hammer and a DAS8000 data collector unit. Both notched ( $2 \mathrm{~mm}$ deep notch) and unnotched specimens were also prepared for the impact tests; 15 and $6.21 \mathrm{~J}$ impact energy was used for the unnotched and notched specimens respectively. All tests were executed at room temperature and at a relative humidity of $60 \%$. 6 specimens were tested for each measurement.

Melt flow index (MFI) measurements were made by using a Ceast 7027.000 type melt flow indexer at $190^{\circ} \mathrm{C}$ with a load mass of $2.16 \mathrm{~kg}$.

Differential Scanning Calorimetry (DSC) was made on a TA Q2000 type calorimeter by using 3-6 mg of the samples. Heat/cool/heat scans were registered from 0 to $180^{\circ} \mathrm{C}$ with a heating and cooling rate of $5^{\circ} \mathrm{C} / \mathrm{min}$ and nitrogen gas flow was used. Crystallinity was calculated according to the theoretical enthalpy of fusion of $100 \%$ crystalline PLA $(93.0 \mathrm{~J} / \mathrm{g}$ ) [33] by using Equation (1), where the basalt fibre content was also taken into consideration:

$X=\frac{\Delta H_{\mathrm{m}}-\Delta H_{\mathrm{cc}}}{\Delta H_{\mathrm{f}} \cdot(1-\alpha)} \cdot 100$

where $X[\%]$ is the crystallinity, $\Delta H_{\mathrm{m}}[\mathrm{J} / \mathrm{g}]$ and $\Delta H_{\mathrm{cc}}$ $[\mathrm{J} / \mathrm{g}]$ is the enthalpy of fusion and the enthalpy of cold-crystallisation, $\Delta H_{\mathrm{f}}[\mathrm{J} / \mathrm{g}]$ is the enthalpy of fusion for $100 \%$ crystalline PLA and $\alpha[-]$ is the mass fraction of basalt fibres.

Dynamic Mechanical Analysis (DMA) was performed on a TA Q800 tester by using the injection moulded three-point bending specimens and dual cantilever. The dual cantilever was used in order to obtain storage modulus information above glass transition temperature $\left(T_{\mathrm{g}}\right)$. Amplitude of $20 \mu \mathrm{m}$ with a span length of $35 \mathrm{~mm}$ and a frequency of $1 \mathrm{~Hz}$ were used from 0 to $160^{\circ} \mathrm{C}$ at a heating rate of $2{ }^{\circ} \mathrm{C} / \mathrm{min}$.

Heat Deflection Temperature (HDT) was measured by using a Ceast $6505 / 000$ HDT analyser. Injection moulded specimens with a cross-section of $4 \times 10 \mathrm{~mm}$ and support distance of $100 \mathrm{~mm}$ were used. The specific load was $0.45 \mathrm{MPa}$ and the heating rate was $2{ }^{\circ} \mathrm{C} / \mathrm{min}$. The HDT value is obtained when the deflection reached $0.33 \mathrm{~mm}$.

Dimensional stability of the injection moulded, $2 \mathrm{~mm}$ thick flat specimens were analysed by placing them into a heated oven and measuring the flow directional dimensional changes due to increasing temperature. The specimens were placed on a flat glass plate so as to get only dimensional changes and no deflection. The oven was heated to $40,50,60$, 80,100 and $120^{\circ} \mathrm{C}$ for 30 minutes and the dimensions of the specimens were recorded after cooling them to room temperature. These dimensions were compared with the dimensions recorded at room temperature prior to heating by using Equation (2):

$D=\frac{L_{\mathrm{b}}-L_{\mathrm{a}}}{L_{\mathrm{b}}} \cdot 100$

where $D[\%]$ is the dimensional change, $L_{\mathrm{b}}[\mathrm{mm}]$ and $L_{\mathrm{a}}[\mathrm{mm}]$ are the in-flow length of the specimens measured before and after the 30 minute heating process respectively.

The deflection of the specimens was also measured by using the flat specimens placed in the same oven, but in a cantilever to be loaded by their own weight.

Finally, scanning electron microscopy (SEM) was performed by a Jeol JSM 6380LA type electron microscope. The fracture surfaces of the tensile specimens were used for the observations. Prior to observation, $\mathrm{Au} / \mathrm{Pd}$ alloy was sputtered onto the surface to avoid electrostatic charging. 


\section{Results and discussion}

\subsection{Melt flow index analysis}

Prior to injection moulding, the melt flow index of the basalt fibre reinforced PLA composites was analysed (Figure 1).

It is found that by the incorporation of basalt fibres the MFI values decreased, what was expected, at the same time above $15 \mathrm{wt} \%$ the MFI values did not change essentially. This could be explained by the increased MFI of the PLA phase itself which compensated the MFI decreasing effect of the fibres. The increased MFI of PLA was possibly due to increased shear caused by the higher amount of fibres and due to higher residence times caused by lower output of the extruder during melt blending. It is also worth to note that by using silane treated basalt fibres the MFI values decreased more compared to untreated basalt fibre composites. This difference could be related to the adhesion between the fibres and the matrix and thus it suggest better compatibility between silane treated basalt fibres and PLA than between untreated basalt fibres and PLA presumably because the basalt fibres are distributed more uniformly - due to the silane treatment - in the melt, which thus becomes more viscous.

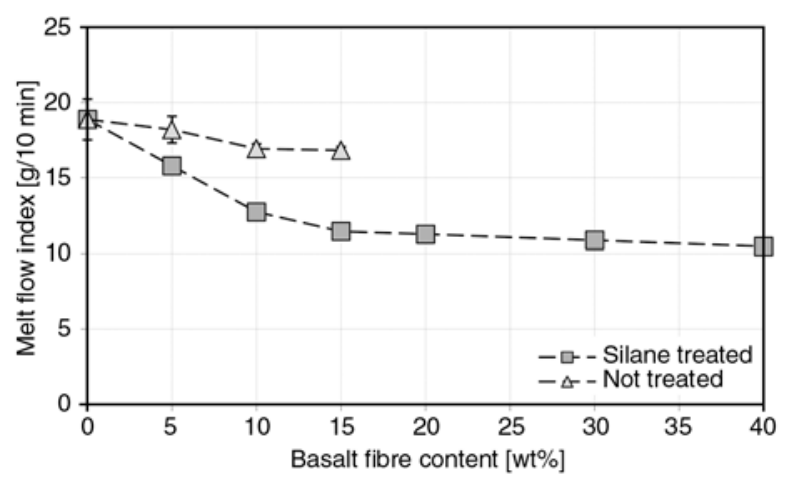

Figure 1. Melt flow index of the basalt fibre reinforced PLA composites

\subsection{Mechanical properties}

The mechanical properties of the injection moulded specimens were analysed by using quasi-static tensile and three-point bending tests and notched and unnotched Charpy impact tests. The tensile strength and the tensile modulus results can be seen in (Figure 2, Figure 3). Note that standard deviation is presented in all of the diagrams in the entire paper, however, in most cases it is so low, that the markings overlie it.

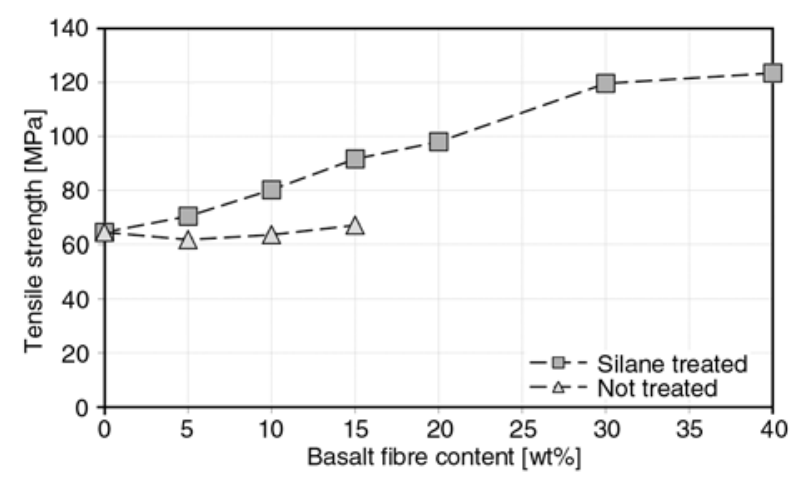

Figure 2. Tensile strength of the basalt fibre reinforced PLA composites

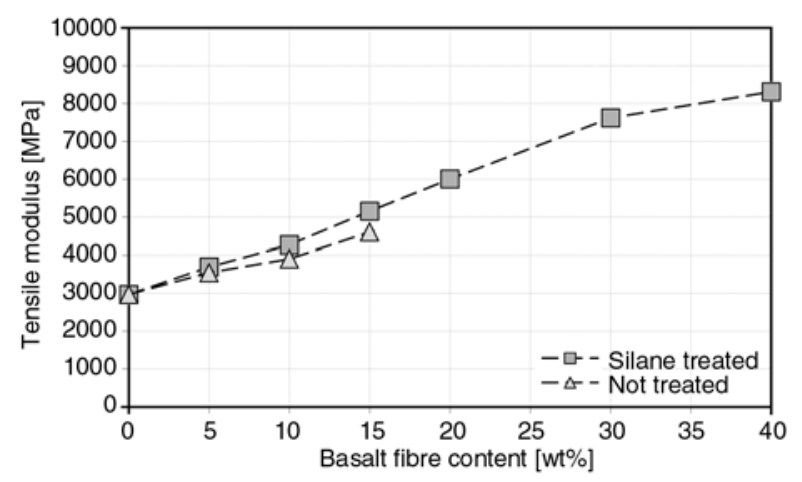

Figure 3. Tensile modulus of the basalt fibre reinforced PLA composites

It is obvious according to Figure 2 and Figure 3 that silane treated basalt fibre composites have superior mechanical properties (higher strength, the same order of magnitude of modulus) compared to the untreated basalt fibre composites, thus by using the silane treated basalt fibres, the composites reached a tensile strength of $123 \mathrm{MPa}$, a tensile modulus of over $8 \mathrm{GPa}$ at the cost of minimal $(0.6 \%)$ reduction of strain (measured but not presented). It was found that by increasing basalt fibre content both tensile strength and tensile modulus increased linearly in the $0-30 \mathrm{wt} \%$ basalt fibre content range. Moreover, it is also worth to note that there is low difference between the strength and modulus of 30 and $40 \mathrm{wt} \%$ silane treated basalt fibre reinforced PLA composites thus compared to $30 \mathrm{wt} \%$ basalt fibre content by adding another $10 \mathrm{wt} \%$ did not have significant reinforcing effect which suggest that at $40 \mathrm{wt} \%$ major fibre brakeage occurred probably caused by the fibre-fibre friction due to the increased amount of fibres.

The three-point bending tests show similar result compared to tensile tests (Figure 4, Figure 5).

The composites reached a flexural strength of $185 \mathrm{MPa}$ and a flexural modulus of over $12 \mathrm{GPa}$. 


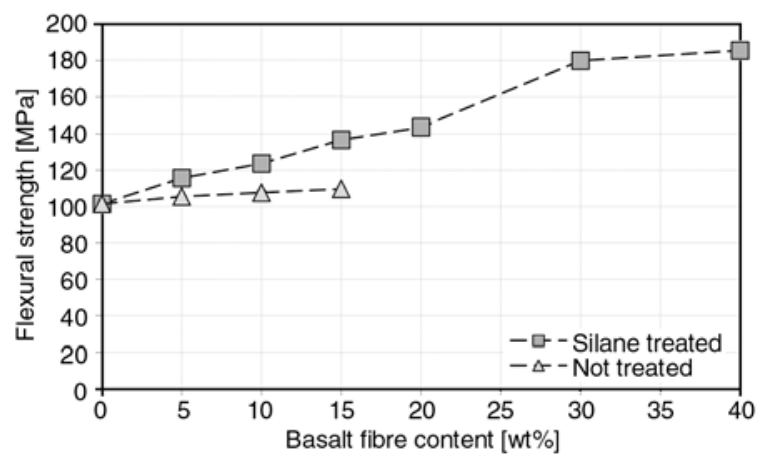

Figure 4. Flexural strength of the basalt fibre reinforced PLA compositesb

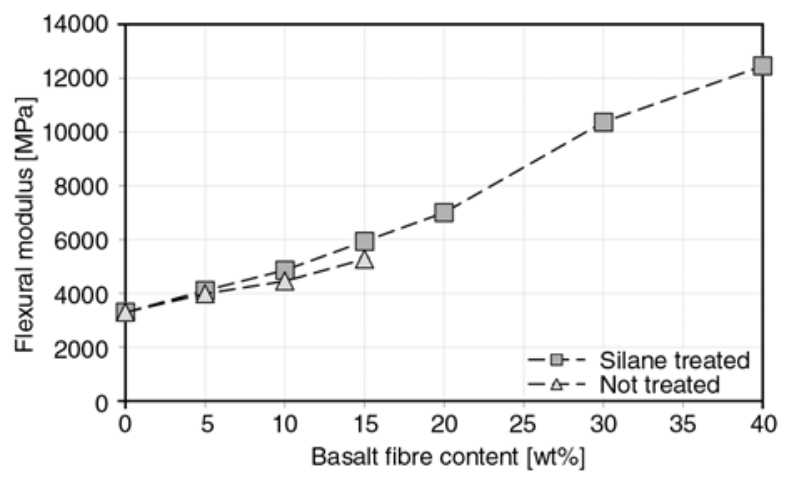

Figure 5. Flexural modulus of the basalt fibre reinforced PLA composites

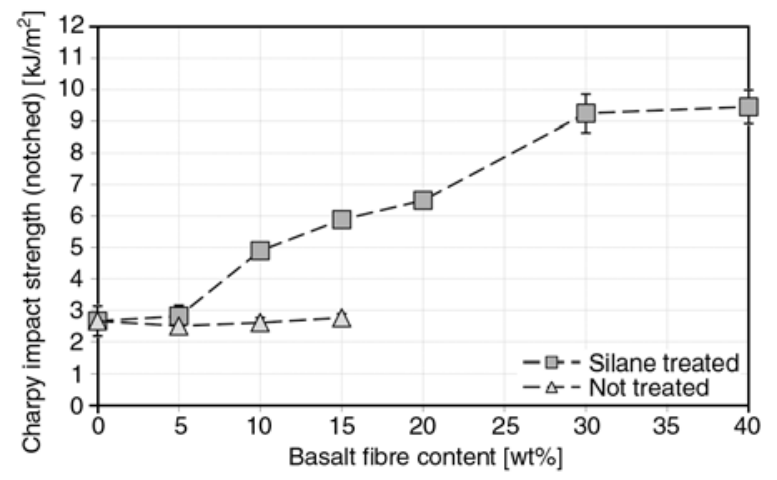

Figure 6. Charpy impact strength (notched) of the basalt fibre reinforced PLA composites

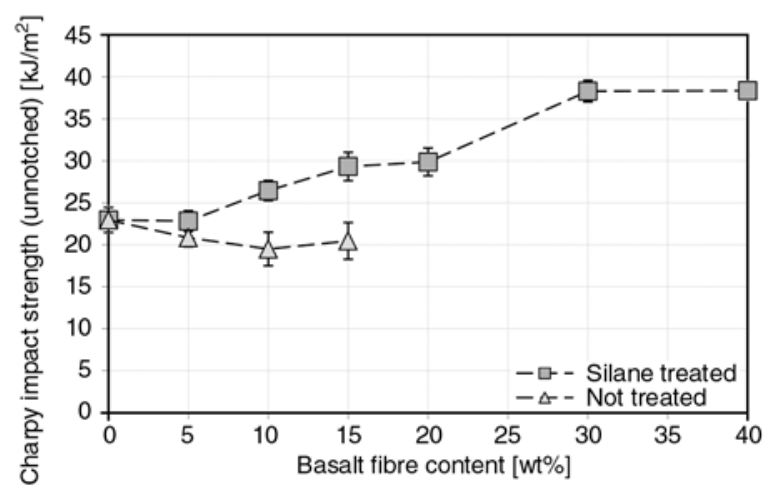

Figure 7. Charpy impact strength (unnotched) of the basalt fibre reinforced PLA composites
Correspondingly to tensile properties, the flexural properties were also linearly related to the basalt fibre content in the range of $0-30 \mathrm{wt} \%$ basalt, and the possible fibre breakage can also be observed in the flexural strength of the $40 \mathrm{wt} \%$ basalt fibre content composite, as it is almost the same as the flexural strength of the $30 \mathrm{wt} \%$ basalt fibre content composite. Finally, the notched (Figure 6) and unnotched (Figure 7) Charpy impact tests revealed that the critically low impact strength of PLA, especially for engineering applications can be significantly increased by the incorporation of basalt fibres.

By incorporating $30 \mathrm{wt} \%$ basalt fibres the notched and unnotched Charpy impact strength of PLA of 2.7 and $23.0 \mathrm{~kJ} / \mathrm{m}^{2}$ increased to 9.3 (by $244 \%$ ) and $38.3 \mathrm{~kJ} / \mathrm{m}^{2}$ (by $67 \%$ ) respectively. Charpy impact test results as well as tensile and bending test results also confirm that above $30 \mathrm{wt} \%$ basalt fibre content no significant reinforcing effect can be achieved due to probably increased fibre breakage.

All of the above mentioned mechanical properties increased more or less linearly to the basalt fibre content in the range of $0-30 \mathrm{wt} \%$ basalt fibre content range, which is demonstrated by using linear regression. The coefficients for the regression can be found in Table 2 .

The mechanical properties of the injection moulded composites are better compared to results from Liu et al. [28] by 12, 25 and 53\% according to tensile, flexural and Charpy impact strength respectively at same basalt fibre content ( $40 \mathrm{wt} \%)$ and also better compared to result from Kurniawan et al. [29] by 24 and $143 \%$ according to tensile strength and tensile modulus at same basalt fibre content $(25 \mathrm{wt} \%$ (note that $25 \mathrm{wt} \%$ basalt fibre content composite was not fabricated in this research, but due to the highly linear relationship, the properties were determined by interpolation)). The reason for the better properties can be found in the higher drying tem-

Table 2. Linear regression coefficients for the mechanical properties between $0-30 \mathrm{wt} \%$ basalt fibre content

\begin{tabular}{|l|c|c|}
\hline \multicolumn{1}{|c|}{ Mechanical property } & Gradient & $\mathbf{R}^{\mathbf{2}}$ \\
\hline Tensile strength & $1.77 \mathrm{MPa} /$ basalt wt $\%$ & 0.99 \\
\hline Tensile modulus & $151.2 \mathrm{MPa} /$ basalt wt $\%$ & 0.99 \\
\hline Flexural strength & $2.44 \mathrm{MPa} /$ basalt $\mathrm{wt} \%$ & 0.98 \\
\hline Flexural modulus & $209.5 \mathrm{MPa} / \mathrm{basalt} \mathrm{wt} \%$ & 0.96 \\
\hline $\begin{array}{l}\text { Charpy impact strength } \\
\text { (notched) }\end{array}$ & $0.227\left[\mathrm{~kJ} / \mathrm{m}^{2}\right] /$ basalt wt $\%$ & 0.97 \\
\hline $\begin{array}{l}\text { Charpy impact strength } \\
\text { (unnotched) }\end{array}$ & $0.518\left[\mathrm{~kJ} / \mathrm{m}^{2}\right] /$ basalt wt $\%$ & 0.94 \\
\hline
\end{tabular}


perature of PLA prior to processing as it is published in our former research [31]. Moreover, these results indicate that the basalt fibre reinforced PLA could be used as durable engineering composite materials, because the developed composite has similar mechanical properties to Polyamide 6 (PA6) reinforced with $15 \mathrm{wt} \%$ glass fibre. A further advantage of the developed composite is, that the above mentioned high mechanical properties can not only be achieved by using long fibres and slow technologies like film-stacking to produce only flat-like products (as is was mentioned in the introduction in the case of plant fibre reinforced biocomposites), but by injection moulding, which is the most versatile thermoplastic processing technology to produce complex, 3D shaped engineering parts with high dimensional accuracy and low cycle times.

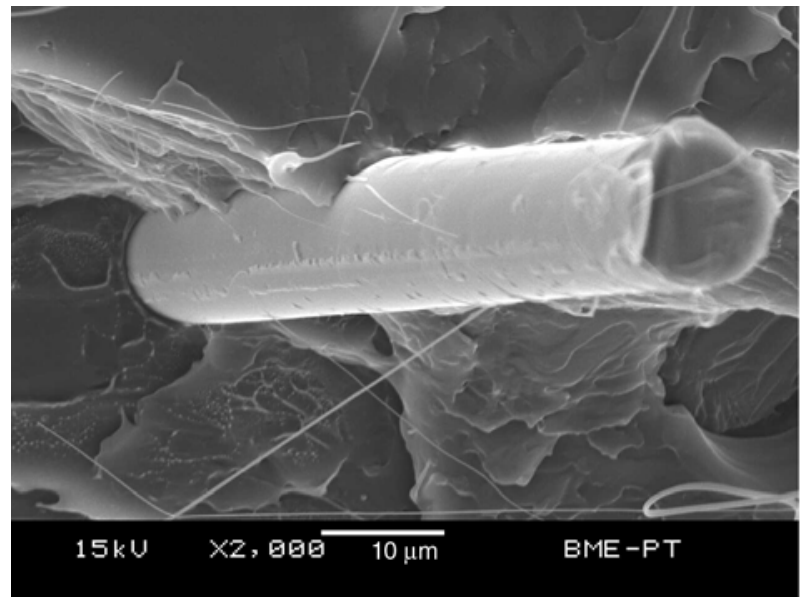

a)

\subsection{Scanning electron microscopy}

Scanning electron microscope (SEM) observations were made on the fracture surface of tensile specimens to evaluate the adhesion between the phases (Figure 8, Figure 9). On the fracture surface of the $15 \mathrm{wt} \%$ basalt fibre reinforced PLA composites without treatment basalt fibres with smooth surface can be observed, which represents inadequate fibre wetting, and moreover a gap between the matrix and the root of the fibres can also be seen in the untreated basalt fibre reinforced composites, which indicates weak adhesion as it could already be seen in the mechanical properties (Figure 8a). On the fracture surface of the composite with the same amount of basalt fibres but with silane treatment, much stronger adhesion can be observed which is denoted by the absence of gap between the fibres

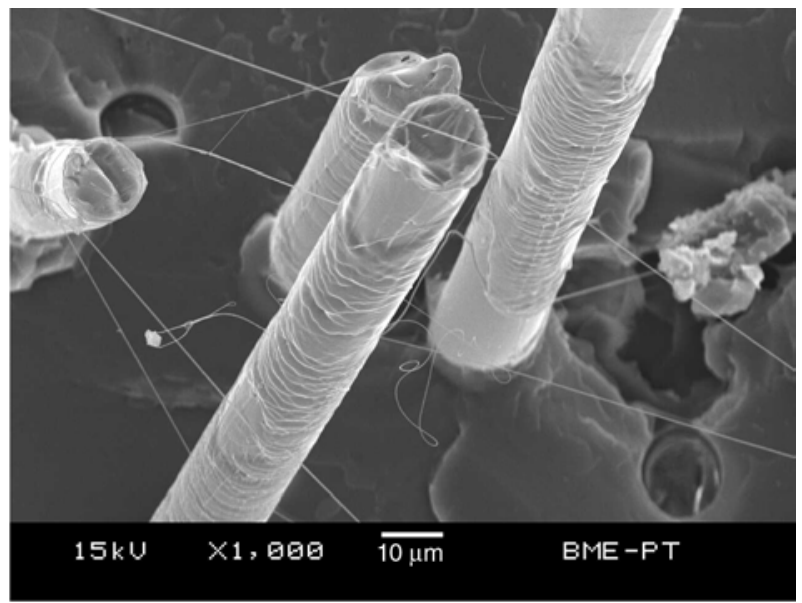

b)

Figure 8. Cross-section of untreated (a) and treated (b), $15 \mathrm{wt} \%$ basalt fibre reinforced PLA composite

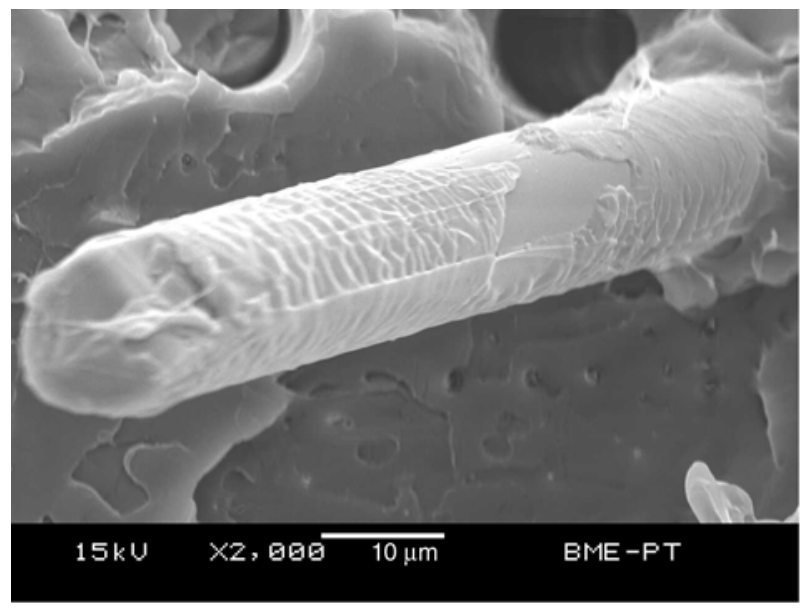

a)

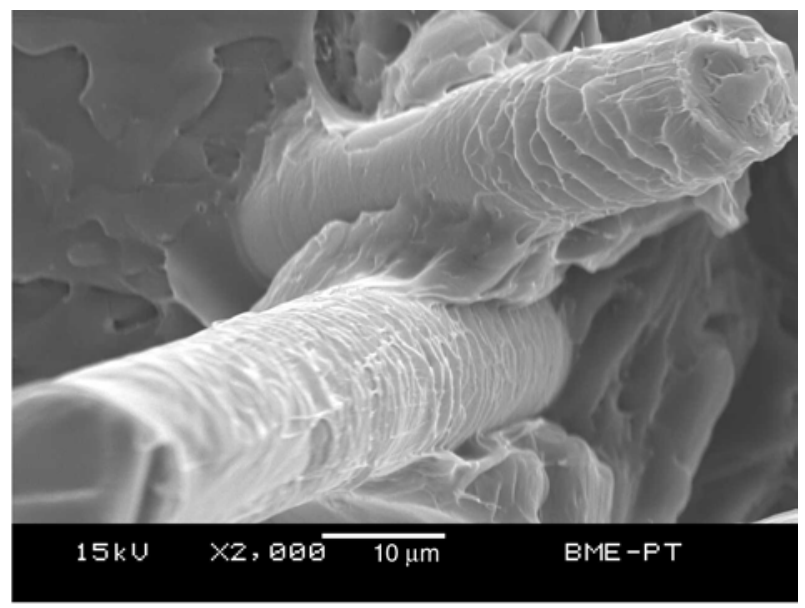

b)

Figure 9. Cross-section of $20 \mathrm{wt} \%$ (a) and $40 \mathrm{wt} \%$ (b) silane treated basalt fibre reinforced PLA composite 
and the matrix, and by the wetting of the fibre by PLA (Figure 8b).

For the 20, 30 and $40 \mathrm{wt} \%$ silane treated basalt fibre reinforced composites (Figure 9), also strong adhesion was found.

On the surface of the silane treated fibres a clear PLA layer can be found which represents excellent adhesion. These results are again better compared to literature data (Liu et al. [28]), where the surface of the basalt fibres were smooth and poorly wetted in spite of the reinforcing effect. Good quality wetting was achieved by Kurniawan et al. [29] by using plasma treatment of the basalt fibres, however only basalt fibre reinforced PLA composites were produced with lower mechanical properties compared to our results.

\subsection{Differential scanning calorimetry}

Differential scanning calorimetry (DSC) was performed by using 3-6 $\mathrm{mg}$ samples taken out from the middle of the cross section of the injection moulded specimens. The cooling DSC scans registered at a cooling rate of $5^{\circ} \mathrm{C} / \mathrm{min}$ are presented in Figure 10 .

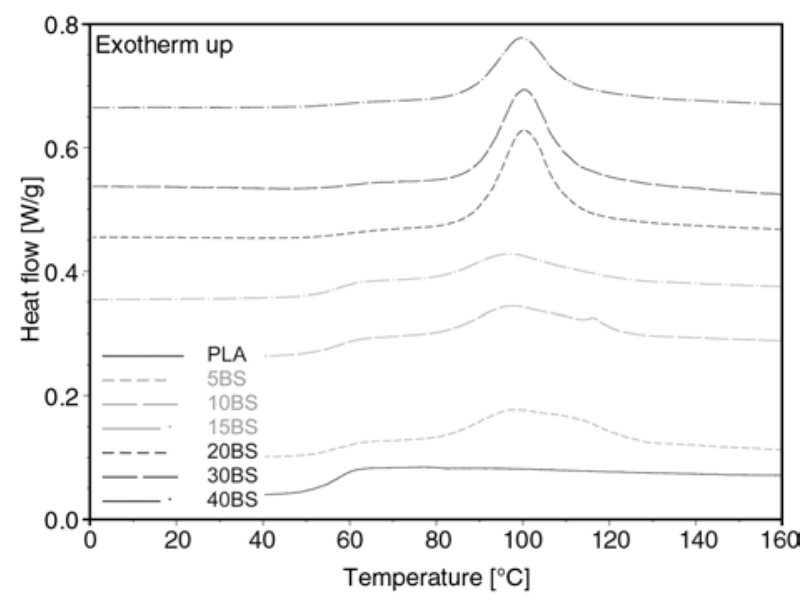

Figure 10. Cooling scan of 5-10-15-20-30-40 wt $\%$ basalt fibre reinforced composites
It can be seen that pure PLA only slightly crystallises and the specimens become transparent during cooling from melt what is a common phenomena according to its very slow crystallisation kinetics, especially when using high cooling rate technologies like injection moulding, thus the material of the pure PLA specimens are to be further referred in the paper as amorphous PLA. At the same time the silane treated and not treated basalt fibres both had nucleating effect which is represented by the higher and higher exothermic peak found around $100^{\circ} \mathrm{C}$ with increasing basalt fibre content. This statement is supported by the quantitative evaluation of the DSC results (Table 3 ). The crystallinity of the injection moulded samples was calculated by the first heating scan and by using Equation (1), while the crystallinity of the samples cooled at $5^{\circ} \mathrm{C} / \mathrm{min}$ was calculated by using the second heating scan.

It is found that at and above $20 \mathrm{wt} \%$ basalt fibre content the nucleating effect of the fibres was enough to develop significant and at the same time the maximum possible crystallinity for PLA, which is around $40-45 \%$. However, this statement is only valid for crystallinity values obtained from the cooling and second heating DSC scan where the cooling and heating rate was set to $5^{\circ} \mathrm{C} / \mathrm{min}$, while the crystallinity of the injection moulded specimens obtained from the first heating scan was naturally much lower, but still significant; around $19 \%$ due to the high cooling rates during processing. Nevertheless, the nucleating effect of basalt fibres suggest that by using further nucleating agents like talc and/or lower cooling rates during processing presumably basalt fibre reinforced semi-crystalline PLA can be produced which has an enormous advantage according to its crystallinity compared to amorphous PLA what is represented in the much higher heat deflec-

Table 3. Crystallinity of basalt fibre reinforced PLA composites

\begin{tabular}{|l|c|c|c|}
\hline \multicolumn{1}{|c|}{ Material } & $\begin{array}{c}\text { Crystallinity of the injection } \\
\text { moulded samples [\%] }\end{array}$ & $\begin{array}{c}\text { Crystallinity of the samples } \\
\text { cooled at 5 } \mathbf{~}^{\circ} \mathbf{m i n} \text { [\%] }\end{array}$ & $\begin{array}{c}\text { Crystallisation peak } \\
\text { temperature [ }{ }^{\circ} \mathbf{C} \text { ] }\end{array}$ \\
\hline Amorphous PLA & 1.1 & 3.0 & - \\
\hline $5 \mathrm{BN}$ & 8.5 & 21.6 & 96 \\
\hline $5 \mathrm{BS}$ & 4.0 & 25.6 & 99 \\
\hline $10 \mathrm{BN}$ & 10.6 & 20.9 & 97 \\
\hline $10 \mathrm{BS}$ & 14.0 & 24.4 & 97 \\
\hline $15 \mathrm{BN}$ & 17.2 & 23.1 & 97 \\
\hline $15 \mathrm{BS}$ & 17.5 & 21.1 & 100 \\
\hline 20BS & 18.7 & 42.9 & 100 \\
\hline $30 \mathrm{BS}$ & 19.0 & 44.2 & 100 \\
\hline $40 \mathrm{BS}$ & 18.5 & 44.8 & \\
\hline
\end{tabular}


tion temperature and thus it would be much more suitable for engineering applications.

\subsection{Dynamic mechanical analysis}

Dynamic mechanical analyses (DMA) were performed to examine the usability of the developed composites in the temperature range of $0-160^{\circ} \mathrm{C}$ and especially in the critical range above $T_{\mathrm{g}}$. Due to the slow crystallisation of PLA, it remains mostly amorphous during injection moulding, thus the dramatic drop in storage modulus at $T_{\mathrm{g}}$ and the increase in storage modulus caused by cold-crystallisation in the temperature range of $80-120^{\circ} \mathrm{C}$ can be observed (Figure 11).

Naturally the basalt fibres increase the storage modulus; the silane treated basalt fibres increased it more significantly than the untreated ones due to the better adhesion proved previously by the SEM and mechanical test results. It can also be seen that the nucleating effect of basalt fibres at and above $20 \mathrm{wt} \%$ basalt fibre content observed by DSC was not enough to develop significant crystallinity in PLA during injection moulding to avoid the dramatic drop in storage modulus at $T_{\mathrm{g}}$, thus this high storage modulus loss still can be observed for all of the basalt fibre reinforced composites (Figure 12). For further analysis the DMA curve of semi-crystalline PLA (C-PLA) was also registered (semi-crystalline PLA sample was made by annealing at $120^{\circ} \mathrm{C}$ for 1 hour to gain maximum possible crystallinity). By using $40 \mathrm{wt} \%$ silane treated basalt fibres, the storage modulus above $T_{\mathrm{g}}$ was only reduced to the same order of magnitude as the storage modulus of semi-crystalline PLA (Figure 13), which is important because semi-crystalline PLA has a HDT value

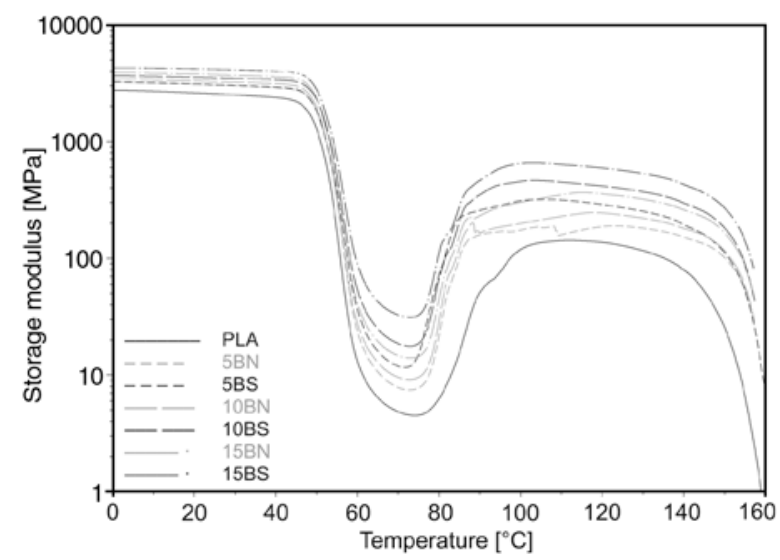

Figure 11. Storage modulus of amorphous PLA (PLA), and 5-10-15 wt $\%$ basalt fibre reinforced composites with and without silane treatment

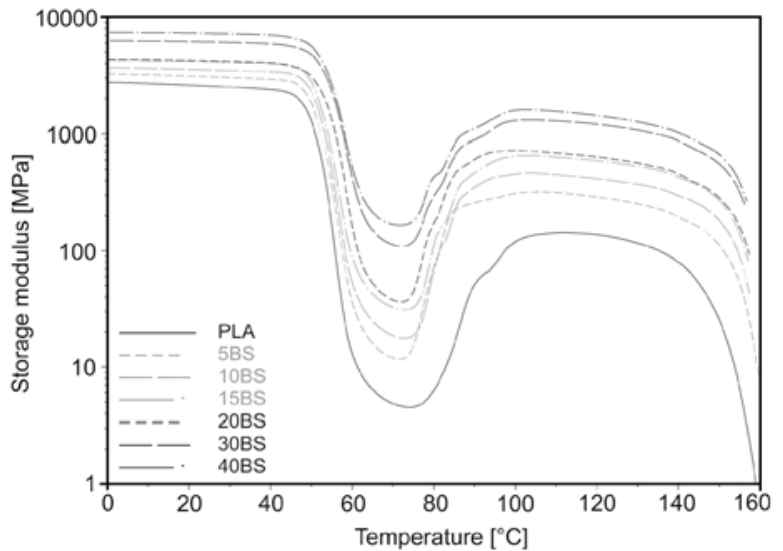

Figure 12. Storage modulus of amorphous PLA (PLA) and 5-10-15-20-30-40 wt \% basalt fibre reinforced composites with silane treatment

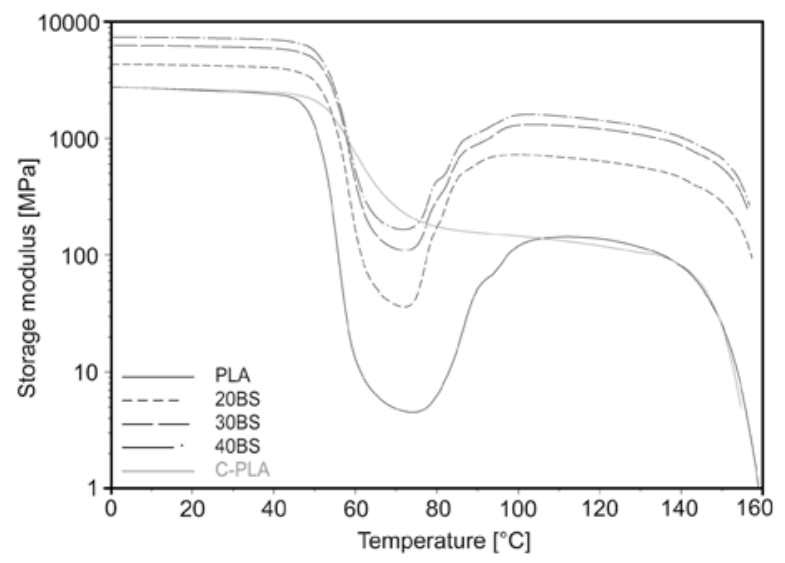

Figure 13. Storage modulus of amorphous PLA (PLA), semi-crystalline PLA (C-PLA) and 20-30-40 wt\% basalt fibre reinforced composites with silane treatment

of $127^{\circ} \mathrm{C}$ and considered as heat resistant compared to amorphous PLA, which has a HDT value of $54^{\circ} \mathrm{C}$.

However, semi-crystalline PLA still has, but only slightly higher storage modulus in the range of 58$76^{\circ} \mathrm{C}$ than the $40 \mathrm{wt} \%$ basalt reinforced composite. The storage modulus values of PLA, semi-crystalline PLA and the basalt fibre reinforced PLA composites at $40,120^{\circ} \mathrm{C}$ and the most critical and lowest storage modulus values between $70-80^{\circ} \mathrm{C}$ (above $T_{\mathrm{g}}$ but before cold-crystallisation) can be seen in Table 4.

It can be seen that by the incorporation of basalt fibres, the storage modulus increased linearly to reinforcement content and reached an around threetimes higher modulus at $40^{\circ} \mathrm{C}$ and ten-times higher modulus at $120^{\circ} \mathrm{C}$. By using linear regression it was found that the storage modulus at $40^{\circ} \mathrm{C}$ increased with a gradient of $114.0 \mathrm{MPa} / \mathrm{basalt} \mathrm{wt} \%$ content 
Table 4. Storage modulus vales of amorphous PLA, semi-crysatlline PLA and basalt fibre reinforced PLA composites

\begin{tabular}{|l|c|c|c|}
\hline \multicolumn{1}{|c|}{ Material } & $\begin{array}{c}\text { Storage modulus at } \mathbf{4 0}^{\circ} \mathbf{C} \\
{[\mathbf{M P a}]}\end{array}$ & $\begin{array}{c}\text { Storage modulus at } \mathbf{~ 1 2 0}^{\circ} \mathbf{C} \\
{[\mathbf{M P a}]}\end{array}$ & $\begin{array}{c}\text { Lowest storage modulus } \\
\text { between } \mathbf{7 0}-\mathbf{8 0}{ }^{\circ} \mathbf{C}[\mathbf{M P a}]\end{array}$ \\
\hline Amorphous PLA & 2390 & 140 & $5\left(\right.$ at $\left.74^{\circ} \mathrm{C}\right)$ \\
\hline Semi-crystalline PLA & 2490 & 130 & $250\left(\right.$ at $\left.70^{\circ} \mathrm{C}\right)$ \\
\hline $5 \mathrm{BN}$ & 2900 & 190 & $7\left(\right.$ at $\left.73^{\circ} \mathrm{C}\right)$ \\
\hline $5 \mathrm{BS}$ & 2920 & 290 & $12\left(\right.$ at $\left.72^{\circ} \mathrm{C}\right)$ \\
\hline $10 \mathrm{BN}$ & 3130 & 250 & $9\left(\right.$ at $\left.72^{\circ} \mathrm{C}\right)$ \\
\hline $10 \mathrm{BS}$ & 3380 & 420 & $18\left(\right.$ at $\left.73^{\circ} \mathrm{C}\right)$ \\
\hline $15 \mathrm{BN}$ & 3600 & 360 & $14\left(\right.$ at $\left.73^{\circ} \mathrm{C}\right)$ \\
\hline $15 \mathrm{BS}$ & 4000 & 590 & $31\left(\right.$ at $\left.73^{\circ} \mathrm{C}\right)$ \\
\hline 20BS & 4500 & 780 & $45\left(\right.$ at $\left.72^{\circ} \mathrm{C}\right)$ \\
\hline $30 \mathrm{BS}$ & 5900 & 1200 & $109\left(\right.$ at $\left.72^{\circ} \mathrm{C}\right)$ \\
\hline $40 \mathrm{BS}$ & 7030 & 1430 & $166\left(\right.$ at $\left.71^{\circ} \mathrm{C}\right)$ \\
\hline
\end{tabular}

$\left(R^{2}=0,99\right)$, while the storage modulus at $120^{\circ} \mathrm{C}$ increased with a gradient of $32.9 \mathrm{MPa} /$ basalt wt $\%$ content $\left(R^{2}=0,99\right)$ according to silane treated basalt fibres.

\subsection{Dimensional stability}

Dimensional stability of the basalt fibre reinforced PLA composites was examined by placing them into a heated oven and measuring the changes in flow directional (longitudinal) dimensions after heating by using Equation (2). Naturally, it is found that basalt fibres restrain deformation, and it can be observed that the main deformation occurs above $T_{\mathrm{g}}$, which is caused by the specific volume change due to cold-crystallisation (Figure 14).

It is again found that basalt fibres with silane treatment are much more effective than untreated basalt fibres, this time in reducing deformation. With increasing silane treated basalt fibre content, the longitudinal deformation of PLA of $5.9 \%$ was reduced to $2.6,1.6,1.1,0.7,0.5$ and $0.5 \%$ according to $5-10-15-20-30-40 \mathrm{wt} \%$ basalt fibre content respectively (Figure 15).

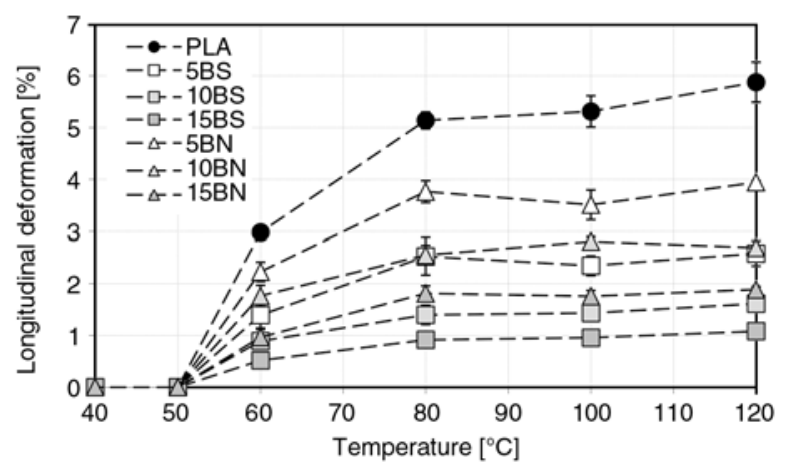

Figure 14. Longitudinal deformation of PLA and 5-10$15 \mathrm{wt} \%$ basalt fibre reinforced composites with and without silane treatment
The dimensional stability of the specimens was also analysed with another method by placing them in a cantilever and registering the deflection caused by the increasing heat and the own weight of the specimens. It was observed that the deflection of the pure PLA was significantly reduced (Figure 16), thus by incorporating basalt fires, the dimensional stability of the specimens highly increased.

It is again demonstrated that silane treated basalt fibres were much more effective than untreated fibres in reducing the deflection of the specimens. By using the same amount of basalt fibres, silane

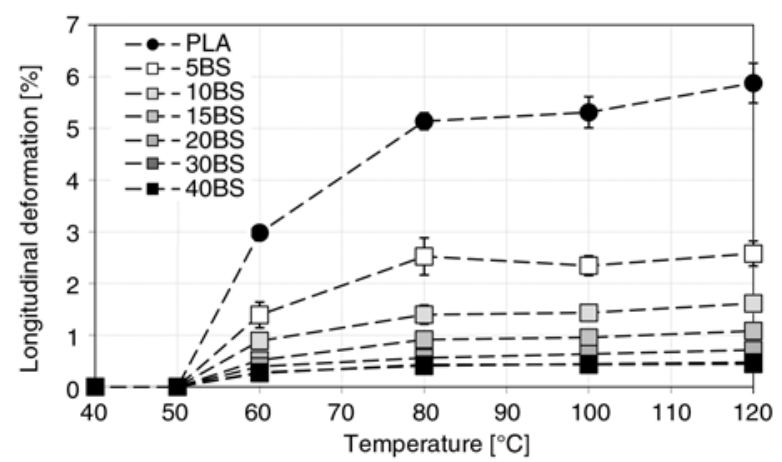

Figure 15. Longitudinal deformation of PLA and 5-10-1520-30-40 wt\% basalt fibre reinforced composites with silane treatment

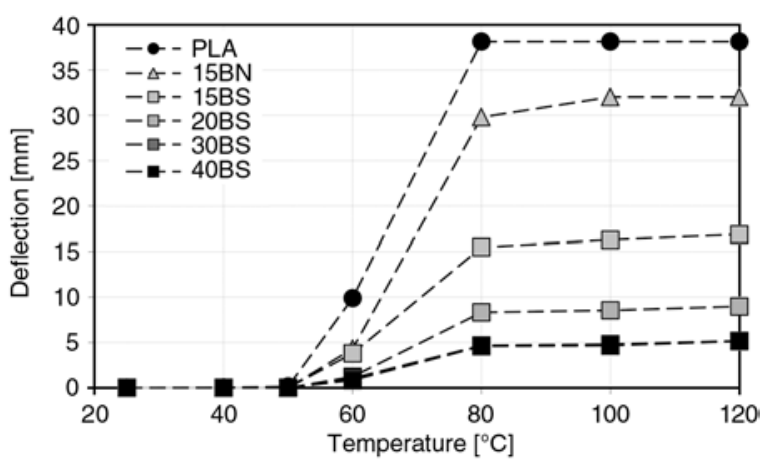

Figure 16. The deflection of the basalt fibre reinforced PLA composites 


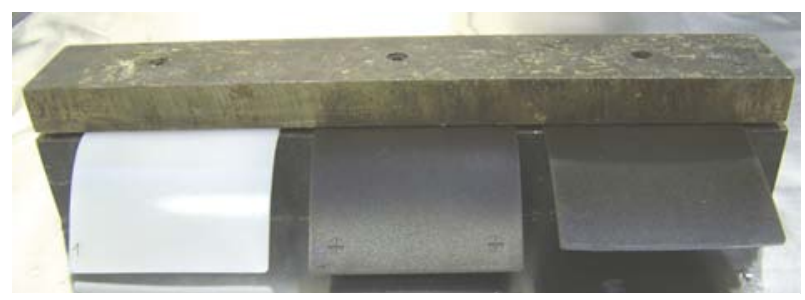

Figure 17. Deflection of the PLA, 15BN, 15BS specimens (from left to right) at $120^{\circ} \mathrm{C}$

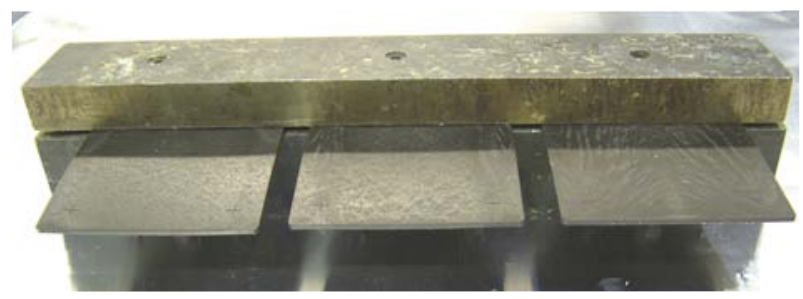

Figure 18. Deflection of the 20BS, 30BS, 40BS specimens (from left to right) at $120^{\circ} \mathrm{C}$

treated basalt fibres reduced the deflection of PLA of more than 40 to $17 \mathrm{~mm}$, while untreated basalt only reduced the deflection to $32 \mathrm{~mm}$. 20, 30 and $40 \mathrm{wt} \%$ silane treated basalt reduced the deflection to 9,5 and $5 \mathrm{~mm}$ respectively as it can be observed in Figure 17 and Figure 18.

As it can be seen, the PLA, 15BN and 15BS composites were highly deformed, while the deflection of the 30BS and 40BS composites was minimal; these latter can be considered as dimensionally stable up to $120^{\circ} \mathrm{C}$.

\subsection{Heat deflection temperature analysis}

For further analysis of the dimensional stability standardised heat deflection temperature (HDT) tests were performed. The standardised HDT analysis with a support distance of $100 \mathrm{~mm}$ only allows $0.33 \mathrm{~mm}$ deflection of the specimens which puts up for much stricter requirements than our dimensional stability test discussed previously. Due to these strict requirements, HDT was only increased by from 54 to $59^{\circ} \mathrm{C}$ by using $40 \mathrm{wt} \%$ of silane treated basalt fibres. At the same time the DMA and dimensional stability test results confirm that $30-40 \mathrm{wt} \%$ basalt fibre reinforced PLA specimens were almost undeformed and nearly passed over the critical $60-80^{\circ} \mathrm{C}$ temperature range where the modulus drops and cold-crystallisation not yet commences. If the stiffness of the PLA can be kept above a certain level in the mentioned critical temperature range, then in the higher temperature range cold-crystallisation could ensure a HDT value of an at least $120^{\circ} \mathrm{C}$.

\section{Conclusions}

In our work the usability of a novel natural fibre, the volcanic rock based basalt fibre was examined as a potential reinforcement for the most promising renewable resource based biodegradable polymer, the poly(lactic acid) (PLA) as well as the comprehensive analysis of basalt fibre reinforced PLA injection moulded composites was performed. 5-10-15$20-30-40 \mathrm{wt} \%$ silane treated and $5-10-15 \mathrm{wt} \%$ untreated basalt fibre reinforced composites were produced by using extrusion and injection moulding. According to our previous results on starch filled PLA, high drying temperature was used $\left(120^{\circ} \mathrm{C}\right)$ to remove the smallest remnants of moisture, which could typically highly deteriorate the adhesion between the phases. As a result silane treated basalt fibre reinforced PLA composites were produced with higher mechanical properties compared to literature. By incorporating $40 \mathrm{wt} \%$ silane treated basalt fibres into PLA, a composite was fabricated with a tensile and flexural strength of 124 and $185 \mathrm{MPa}$, a tensile and flexural modulus of more than 8 and $12 \mathrm{GPa}$ and a Charpy impact strength of $9.5 \mathrm{~kJ} / \mathrm{m}^{2}$ (notched) and $38.4 \mathrm{~kJ} / \mathrm{m}^{2}$ (unnotched) respectively. By using scanning electron microscopy strong adhesion was observed between the phases, and excellent wetting of the silane treated basalt fibres was seen, which is again much better compared to literature results. It was found by using differential scanning calorimetry that basalt fibres have nucleating ability on PLA, however, semicrystalline PLA samples with the possible maximum crystallinity of $40-45 \%$ could only be made by using low cooling rate $\left(5^{\circ} \mathrm{C} / \mathrm{min}\right)$ and at least $20 \mathrm{wt} \%$ basalt fibre content. By using injection moulding, and thus high cooling rate, the crystallinity of the basalt fibre reinforced PLA composites reached a lower, but still significant value of $19 \%$. Besides nucleating ability of the basalt fibres, they effectively reduced the deformation and deflection caused by increasing temperature making it a more or less dimensionally stable composite up to $120^{\circ} \mathrm{C}$. According to the DMA results, by incorporating the basalt fibres the storage modulus at 40 and at $120^{\circ} \mathrm{C}$ became three-times higher and ten-times higher compared to the storage modulus of amorphous PLA respectively. Moreover the storage modulus of the $40 \mathrm{wt} \%$ basalt fibre reinforced PLA was in the same order of magnitude of a semi-crystalline PLA 
in the critical temperature range of $60-80^{\circ} \mathrm{C}$ (where amorphous PLA products distort), which is a relevant result, because semi-crystalline PLA has a heat deflection temperature (HDT) of more than $120^{\circ} \mathrm{C}$ and considered as heat stable. At the same time, the storage modulus of semi-crystalline PLA (250 MPa) was still somewhat higher than $40 \mathrm{wt} \%$ basalt fibre reinforced PLA $(166 \mathrm{MPa})$ at $70^{\circ} \mathrm{C}$ and as a result, by using basalt fibres the standard HDT value only increased from 54 to $59^{\circ} \mathrm{C}$. This could be related to the strict HDT test condition requirement which allows only very small deflection, although the siginifcant impovement in dimensional stability in the case of 30 and $40 \mathrm{wt} \%$ basalt fibre reinforced composites compared to PLA was demonstrated. If the stiffness of the basalt fibre reinforced PLA composite can be kept above a certain level and it could pass over the mentioned critical temperature range undeformed, then in the higher temperature range cold-crystallisation could ensure a HDT value of an at least $120^{\circ} \mathrm{C}$. Nevertheless, probably by using further nucleating agents like talc and/or slow cooling rate during processing basalt fibre reinforced semicrystalline PLA composites with a heat deflection temperature of more than $120^{\circ} \mathrm{C}$ can be produced, which is much more suitable for engineering applications. Finally it was demonstrated that it is possible to produce basalt fibre reinforced PLA composites from renewable and natural resources with excellent mechanical properties not only by using low productivity technologies like film-stacking method not to damage the fibres but by using productive extrusion and injection moulding technologies suitable for manufacturing highly accurate, complex, 3D shaped and durable engineering parts with low cycle times.

\section{Acknowledgements}

The authors thank Arburg Hungária Kft. for the Arburg Allrounder 370C 700-290 injection moulding machine and Lenzkes $\mathrm{GmbH}$ for the clamping tool system. This work is connected to the scientific program of the 'Development of quality-oriented and harmonized $\mathrm{R}+\mathrm{D}+\mathrm{I}$ strategy and functional model at BME' project. This project is supported by the New Széchenyi Plan (Project ID: TÁMOP-4.2.1/B-09/ 1/KMR-2010-0002). The work reported in this paper has been developed in the framework of the project 'Talent care and cultivation in the scientific workshops of BME' project. This project is supported by the grant TÁMOP-4.2.2.B10/1-2010-0009. This paper was supported by the János Bolyai Research Scholarship of the Hungarian Academy of Sciences.

\section{References}

[1] Avérous L.: Biodegradable multiphase systems based on plasticized starch: A review. Journal of Macromolecular Science Part C: Polymer Reviews, 44, 231-274 (2004). DOI: 10.1081/MC-200029326

[2] Yu L., Dean K., Li L.: Polymer blends and composites from renewable resources. Progress in Polymer Science, 31, 576-602 (2006).

DOI: 10.1016/j.progpolymsci.2006.03.002

[3] Ren X.: Biodegradable plastics: A solution or a challenge? Journal of Cleaner Production, 11, 27-40 (2003).

[4] Czigány T., Romhány G., Kovács J. G.: Starch for injection moulding purposes. in 'Handbook of engineering biopolymers: Homopolymers, blends and composites' Hanser, Munich, 81-108 (2007).

[5] Tábi T., Kovács J. G.: Examination of injection moulded thermoplastic maize starch. Express Polymer Letters, 1, 804-809 (2007).

DOI: $10.3144 /$ expresspolymlett.2007.111

[6] Tábi T., Tuba F., Oláh L.: Investigation of time-dependent behavior of starch-based, injection molded biodegradable polymer. Materials Science Forum, 589, 281-286 (2008).

DOI: 10.4028/www.scientific.net/MSF.589.281

[7] Martin O., Avérous L.: Poly(lactic acid): Plasticization and properties of biodegradable multiphase systems. Polymer, 42, 6209-6219 (2001). DOI: 10.1016/S0032-3861(01)00086-6

[8] Yu L., Dean K., Li L.: Polymer blends and composites from renewable resources. Progress in Polymer Science, 31, 576-602 (2006).

DOI: $10.1016 /$ j.progpolymsci.2006.03.002

[9] Lim L-T., Auras R., Rubino M.: Processing technologies for poly(lactic acid). Progress in Polymer Science, 33, 820-852 (2008).

DOI: $10.1016 /$ j.progpolymsci.2008.05.004

[10] Iwatake A., Nogi M., Yano H.: Cellulose nanofiberreinforced polylactic acid. Composites Science and Technology, 68, 2103-2106 (2008). DOI: $10.1016 /$ j.compscitech.2008.03.006

[11] Suryanegara L., Nakagaito A. N., Yano H.: The effect of crystallization of PLA on the thermal and mechanical properties of microfibrillated cellulose-reinforced PLA composites. Composites Science and Technology, 69, 1187-1192 (2009).

DOI: $10.1016 /$ j.compscitech.2009.02.022

[12] Ganster J., Fink H-P., Pinnow M.: High-tenacity manmade cellulose fibre reinforced thermoplastics - Injection moulding compounds with polypropylene and alternative matrices. Composites Part A: Applied Science and Manufacturing, 37, 1796-1804 (2006). DOI: 10.1016/j.compositesa.2005.09.005

[13] Oksman K., Skrifvars M., Selin J-F.: Natural fibres as reinforcement in polylactic acid (PLA) composites. Composites Science and Technology, 63, 1317-1324 (2003).

DOI: $10.1016 / \mathrm{S} 0266-3538(03) 00103-9$ 
[14] Plackett D., Andersen T. L., Pedersen W. B., Nielsen L.: Biodegradable composites based on L-polylactide and jute fibres. Composites Science and Technology, 63, 1287-1296 (2003). DOI: 10.1016/S0266-3538(03)00100-3

[15] Bodros E., Pillin I., Montrelay N., Baley C.: Could biopolymers reinforced by randomly scattered flax fibre be used in structural applications? Composites Science and Technology, 67, 462-470 (2007). DOI: 10.1016/j.compscitech.2006.08.024

[16] Bax B., Müssig J.: Impact and tensile properties of PLA/Cordenka and PLA/flax composites. Composites Science and Technology, 68, 1601-1607 (2008). DOI: $10.1016 /$ j.compscitech.2008.01.004

[17] Huda M. S., Drzal L. T., Mohanty A. K., Misra M.: Chopped glass and recycled newspaper as reinforcement fibers in injection molded poly(lactic acid) (PLA) composites: A comparative study. Composites Science and Technology, 66, 1813-1824 (2006). DOI: $10.1016 /$ j.compscitech.2005.10.015

[18] Anuar H., Zuraida A., Kovács J. G., Tábi T.: Improvement of mechanical properties of injection-molded polylactic acid-kenaf fiber biocomposite. Journal of Thermoplastic Composite Materials, 25, 153-164 (2012).

DOI: $10.1177 / 0892705711408984$

[19] Gur'ev V. V., Neproshin E. I., Mostovoi G. E.: The effect of basalt fiber production technology on mechanical properties of fiber. Glass and Ceramics, 58, 62-65 (2001).

DOI: 10.1023/A:1010901615857

[20] Czigány T.: Special manufacturing and characteristics of basalt fiber reinforced polypropylene composites: Mechanical properties and acoustic emission study. Composites Science and Technology, 66, 3210-3220 (2006).

DOI: 10.1016/j.compscitech.2005.07.007

[21] Czigány T. Deák T. Tamás P.: Discontinuous basalt and glass fiber reinforced PP composites from textile prefabricates: Effects of interfacial modification on the mechanical performance. Composite Interfaces, 15, 697-707 (2008).

DOI: $10.1163 / 156855408786778302$

[22] Militký J., Kovačič V., Rubnerová J.: Influence of thermal treatment on tensile failure of basalt fibers. Engineering Fracture Mechanics, 69, 1025-1033 (2002).

DOI: 10.1016/S0013-7944(01)00119-9

[23] Wei B., Cao H., Song S.: Tensile behavior contrast of basalt and glass fibers after chemical treatment. Materials and Design, 31, 4244-4250 (2010). DOI: $10.1016 /$ j.matdes.2010.04.009
[24] Wei B., Cao H., Song S.: Environmental resistance and mechanical performance of basalt and glass fibers. Materials Science and Engineering: A, 527, 47084715 (2010). DOI: $10.1016 /$ j.msea.2010.04.021

[25] Czigány T., Pölöskei K., Karger-Kocsis J.: Fracture and failure behavior of basalt fiber mat-reinforced vinylester/epoxy hybrid resins as a function of resin composition and fiber surface treatment. Journal of Materials Science, 40, 5609-5618 (2005). DOI: $10.1007 / \mathrm{s} 10853-005-1273-8$

[26] Matkó S., Anna P, Marosi G., Szép A., Keszei S., Czigány T., Pölöskei K.: Use of reactive surfactants in basalt fiber reinforced polypropylene composites. Macromolecular Symposia, 202, 255-267 (2003).

DOI: $10.1002 /$ masy.200351222

[27] Deák T., Czigány T., Tamás P., Németh Cs.: Enhancement of interfacial properties of basalt fiber reinforced nylon 6 matrix composites with silane coupling agents. Express Polymer Letters, 4, 590-598 (2010). DOI: $10.3144 /$ expresspolymlett.2010.74

[28] Liu T., Yu F., Yu X., Zhao X., Lu A., Wang J.: Basalt fiber reinforced and elastomer toughened polylactide composites: Mechanical properties, rheology, crystallization, and morphology. Journal of Applied Polymer Science, 125, 1292-1301 (2012).

DOI: 10.1002/app.34995

[29] Kurniawan D., Kim B. S., Lee H. Y., Lim J. Y.: Atmospheric pressure glow discharge plasma polymerization for surface treatment on sized basalt fiber/polylactic acid composites. Composites Part B: Engineering, 43, 1010-1014 (2012).

DOI: 10.1016/j.compositesb.2011.11.007

[30] Chen X., Li Y., Gu N.: A novel basalt fiber-reinforced polylactic acid composite for hard tissue repair. Biomedical Materials, 5, 044104/1-044104/8 (2010).

DOI: $10.1088 / 1748-6041 / 5 / 4 / 044104$

[31] Kovács J. G., Tábi T.: Examination of starch preprocess drying and water absorption of injection-molded starch-filled poly(lactic acid) products. Polymer Engineering and Science, 51, 843-850 (2011).

DOI: $10.1002 /$ pen. 21900

[32] Tábi T., Sajó I. E., Szabó F., Luyt A. S., Kovács J. G.: Crystalline structure of annealed polylactic acid and its relation to processing. Express Polymer Letters, 4, 659-668 (2010).

DOI: $10.3144 /$ expresspolymlett.2010.80

[33] Battegazzore D., Bocchini S., Frache A.: Crystallization kinetics of poly(lactic acid)-talc composites. Express Polymer Letters, 5, 849-858 (2011). DOI: $10.3144 /$ expresspolymlett.2011.84 